\title{
PREDICTORS OF ATRIAL FIBRILLATION AFTER CABG ASSESSED BY TRANSTHORACIC ECHOCARDIOGRAPHY
}

\author{
By \\ Ahmed Abd El-Mageed Ryad Farag, Yasser Radwan Mohammed \\ Radwan and Ahmed Mohammed Salah El-Din Ahmed \\ Department of Cardiology, Faculty of Medicine Al-Azhar University \\ Corresponding author: Ahmed Abd El-Mageed Ryad Farag, \\ E-mail: ryadelfarra@gmail.com
}

\begin{abstract}
Background: Atrial fibrillation is a common complication after coronary artery bypass grafting (CABG) surgery, although it is a benign arrhythmia it may contribute to morbidity, mortality and prolonged hospital stay.

Objective: To evaluate the echocardiographic predictors of atrial fibrillation (AF) after coronary artery bypass grafting.

Patients and methods: Our study was done on 100 patients who underwent CABG at National Heart Institute and Al-Azhar University hospitals from June 2020 to December 2020. Personal and medical histories were reviewed. Preoperative data included age, gender, and history of diabetes mellitus, history of hypertension and history of smoking. Intraoperative data included duration of bypass and cross clamping and number of grafts. Postoperative data included use of inotropic agents, revision of ECG during hospital stay, identification of atrial fibrillation and method of termination. Echocardiography was done during their hospital stay for assessment of the following: ejection fraction, TPASE, LV internal dimensions, LV septal and posterior wall thickness, left atrium diameter and LA Volume index, TR velocity and presence of MR. Also Pulsed wave and tissue Doppler of mitral annuli was performed to assess E/A ration, septal e', lateral e', septal E/e' and lateral E/e' and calculation of average E/e' was done.
\end{abstract}

Results: Old age and history of hypertension were predictors of atrial fibrillation after CABG surgery. AF developed more frequent in patients who had used an inotropic agent after surgery and in patients with lower ejection fraction, lower TAPSE, dilated LV internal dimensions, increased LV wall thickness, and dilated left atrium and high LAVI. Our findings indicated that development of postoperative atrial fibrillation (POAF) was more frequent with higher average E/e', septal E/e', lateral E/e' velocities and lower septal e' velocity.

Conclusion: Patients who had postoperative impaired LV and RV functions and increased LAVI and LA diameter experienced more frequent POAF than others. Also, higher average E/e', septal E/e', lateral E/e' and lower e' velocities were associated with higher incidence of POAF.

Keywords: Atrial fibrillation, POAF, CABG, Transthoracic echocardiography.

\section{INTRODUCTION}

New-onset postoperative atrial fibrillation (POAF) complicates approximately $20-60 \%$ of all cardiac surgical procedures and is associated with increased periprocedural mortality and morbidity, prolonged hospital stay, increased costs, and worse long-term survival. The true incidence of POAF following cardiac surgery remains somewhat unclear due to variability in 
methods of detection and definitions of POAF (Gudbjartsson et al., 2020). Its causes are multifactorial, and models to stratify patients into risk categories are progressing but a consistent, evidencebased system has not yet been developed. Pharmacologic and surgical interventions to prevent and treat this complication have been an area of ongoing research and recent societal guidelines reflect this (Burrage et al., 2019).

POAF engenders multiple effects on the cardiopulmonary hemodynamic, tachyarrhythmia being the most common presentation. The rapid irregular ventricular rate can result in insufficient coronary flow to compensate myocardial oxygen demand, leading to myocardial ischemia. Furthermore, decreased diastolic filling time and cardiac output are important physiological consequences of tachyarrhythmias (Gudbjartsson et al., 2020).

The POAF was reported to be associated with greater in-hospital mortality, prolonged hospital stays. In addition, the long-term survival was worse in patients who developed POAF. Patients who develop POAF incur additional hospital treatment cost and 2 to 4 fold increased risk of stroke, reoperation for bleeding, infection, renal or respiratory failure, cardiac arrest, cerebral complications and need for permanent pacemaker placement (Greenberg et al., 2017).

A history of atrial fibrillation and indexed left atrial maximal volume are the best predictors of the occurrence of postoperative atrial fibrillation following coronary artery bypass graft. The identification of high risk population of postoperative atrial fibrillation using these two factors could lead to the development of targeted strategies to limit this frequent complication in these patients (Magne et al., 2019).

In most patients, POAF will spontaneously convert to sinus rhythm within 24 hours after surgery. In hemodynamically stable patients, correction of predisposing factors such as hypoxia, anemia, and electrolyte imbalance, should be the first step in the management of POAF (Bidar et al., 2013). In case of hemodynamically unstable patients, cardioversion to sinus rhythm by direct current or pharmacologically with ibutilide or amiodarone, should be pursued. Also if patients are highly symptomatic or when rate control is difficult to achieve, electrical direct current shock is recommended (Members et al., 2012).

The aim of this study was to evaluate the echocardiographic predictors of $\mathrm{AF}$ after CABG.

\section{PATIENTS AND METHODS}

Our study was conducted at National Heart Institute and Al-Azhar University hospitals from June 2020 to December 2020 and was a prospective observational study on 100 patients who had been operated coronary artery bypass grafting surgery and had fulfilled our inclusion criteria.

Inclusion Criteria: Patients who had underwent $\mathrm{CABG}>18$ years old.

\section{Exclusion Criteria:}

1. History of any form of preoperative AF. 
2. History of myocardial infarction less than 2 weeks before the surgery.

3. Unstable angina.

4. Patients with valvular or combined valve and CABG surgeries.

5. Bypass time more than $100 \mathrm{~min}$ or cross clamp time more than $60 \mathrm{~min}$.

6. Advanced heart block or severe conduction disturbance.

7. An implantable defibrillator.

8. Impaired renal function.

\section{Tools and data collection:}

One hundred patients who had underwent CABG at National Heart Institute and Al-Azhar University hospitals from June 2020 to December 2020. The following data was collected during their hospital stay:

A. Full medical history as documented by the treating physician included age, sex, smoking, DM and hypertension.

B. Intraoperative history as regard bypass time and aortic cross clamp time (aortic cross clamp time > $60 \mathrm{~min}$ and $\mathrm{CPB}$ time $>100 \mathrm{~min}$ were important risk factors and number of grafts.
C. ICU history as regard use of inotropic agents for $>30 \mathrm{~min}$.

D. Development of POAF: AF was detected by 12 leads electrocardiogram monitoring and defined as any documented AF of more than 5 minutes in duration or for any length of time requiring intervention for hemodynamic compromise.

E. Echocardiography: Postoperative echocardiography was done to assess left ventricular systolic function, LV internal dimensions, LV wall thickness, left ventricular diastolic function parameters, left atrial size and indexed volume, right ventricular function by TAPSE.

F. Follow up of the patient throughout duration of hospital stay and determine discharge rhythm.

G. Our protocol was to use amiodarone in hemodynamically stable patients and Direct Current shock for hemodynamically unstable patients.

H. Measurement of the required parameters are illustrated in the next figures:

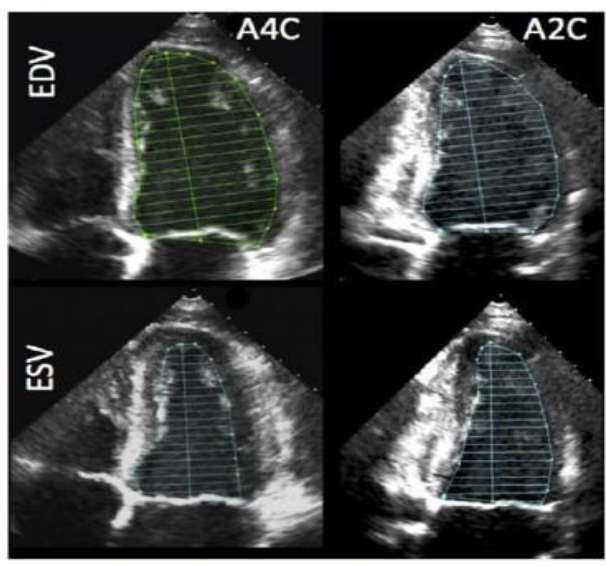

Figure (1): Ejection fraction by biplane Simpson's method. 

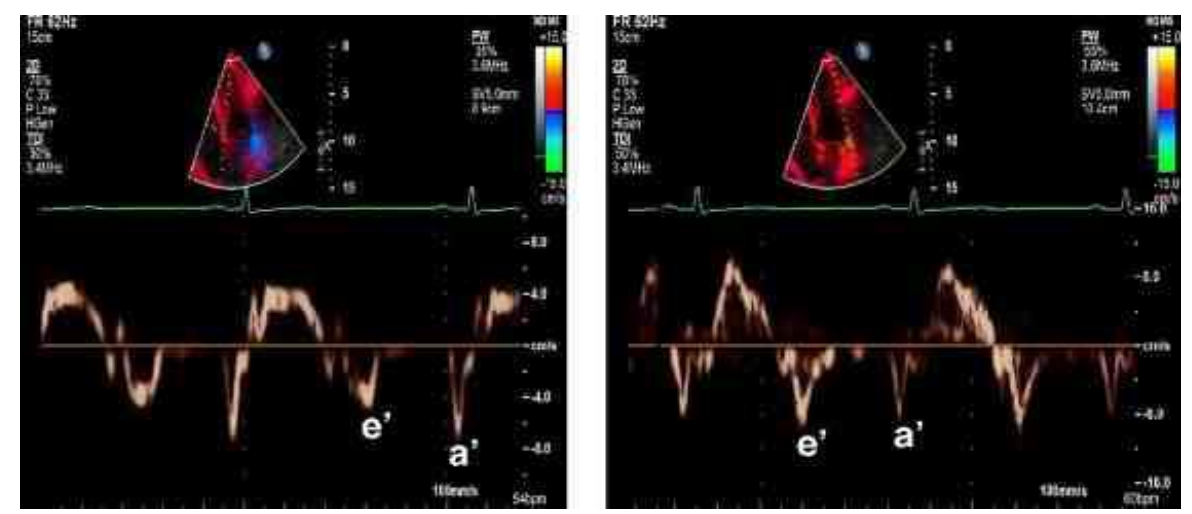

Figure (2): Septal (left) and lateral (right) tissue Doppler recordings.

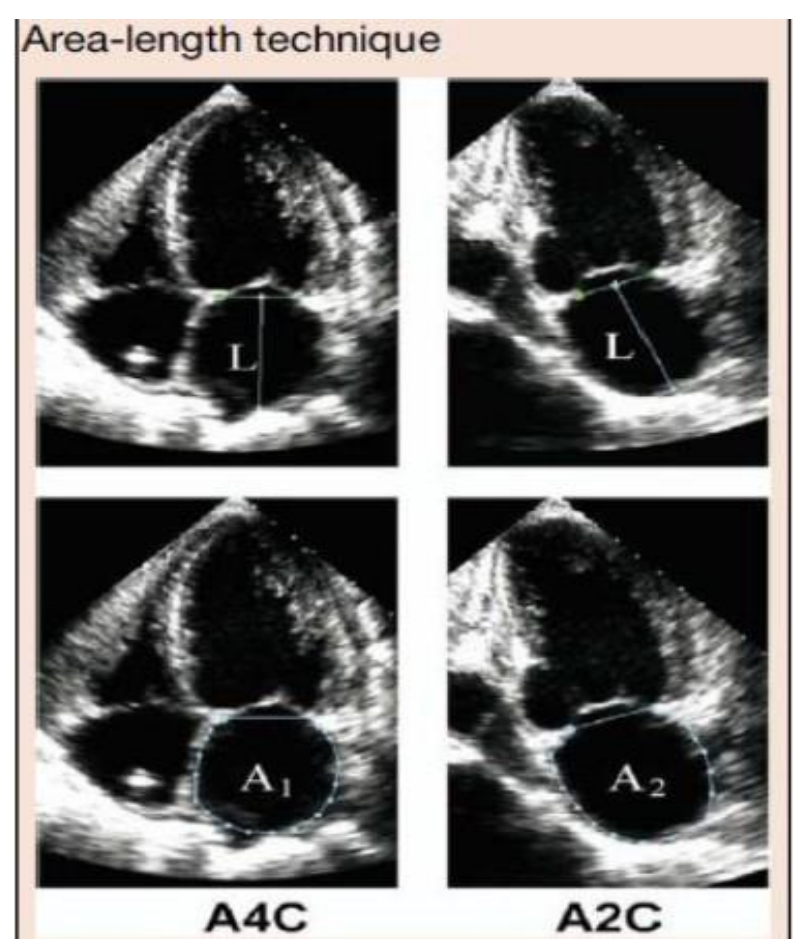

Figure (3): LAV.
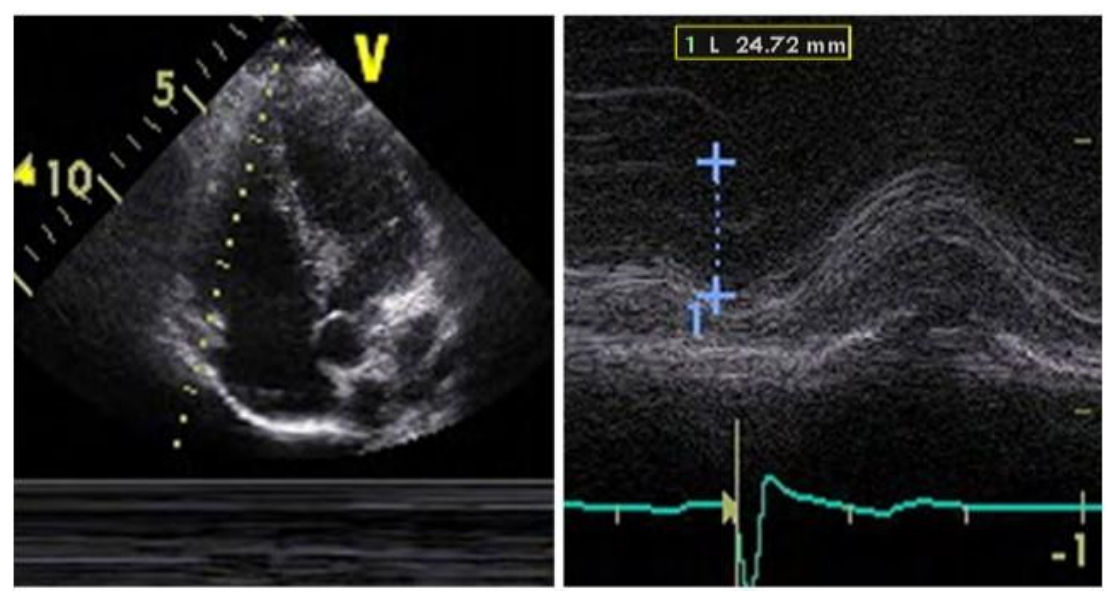

Figure (4): Measurement of tricuspid annular plane systolic excursion (TAPSE). 
An approval of the study was obtained from Al-Azhar University academic and ethical committee.

\section{Statistical analysis:}

The analysis was performed using computer software statistical package for the social science (SPSS, version 20, SPSS Inc., Chicago, Illinois, USA) Description of quantitative (numerical) variables was performed in the form of mean \pm SD. Description of qualitative (categorical) data was performed in the form of number of cases and percent. Appropriate test of associations was performed. Chi square test $(\chi 2)$ to calculate difference between two or more groups of qualitative variables or MannWhitney $U$ test. The significance level was set at p-value of less than 0.05.

\section{RESULTS}

Our study included 100 patients who had CABG. Mean age was 56.24 \pm 7.47 , $81 \%$ of patients were males and $19 \%$ females, $62 \%$ had history of hypertension and $54 \%$ had history of diabetes mellitus (Table 1).

Table (1): Descriptive data of patients

\begin{tabular}{|c|c|c|}
\hline \multirow{2}{*}{ Age } & Mean \pm SD & Total No. $=100$ \\
\cline { 2 - 3 } & Range & $56.24 \pm 7.47$ \\
\hline \multirow{2}{*}{ Gender } & Females & $38-77$ \\
\cline { 2 - 3 } & Males & $19(19.0 \%)$ \\
\hline \multirow{2}{*}{ BSA } & Mean \pm SD & $81(81.0 \%)$ \\
\cline { 2 - 3 } & Range & $1.95 \pm 0.15$ \\
\hline \multirow{2}{*}{ DM } & No & $1.6-2.3$ \\
\cline { 2 - 3 } & Yes & $46(46.0 \%)$ \\
\hline \multirow{2}{*}{ HTN } & No & $54(54.0 \%)$ \\
\cline { 2 - 3 } & Yes & $38(38.0 \%)$ \\
\hline \multirow{2}{*}{ Smoking } & No & $62(62.0 \%)$ \\
\cline { 2 - 3 } & Yes & $49(49.0 \%)$ \\
\hline
\end{tabular}

We had divided patients into two groups; POAF group who had developed atrial fibrillation during their hospital stay and Non-POAF group who didn't develop AF. The incidence of POAF in our study was $24 \%$ representing 24 patients from a total number of 100 patients who have underwent coronary artery bypass grafting surgery. Most cases of POAF have occurred in the second day of the operation with incidence, the lowest incidence has occurred in the fifth day of the operation (Table 2). 
Table (2): Distribution of POAF in the postoperative days

\begin{tabular}{|c|c|c|}
\hline \multicolumn{2}{|c|}{} & Total no. = 100 \\
\hline \multirow{2}{*}{ AF } & No & $76(76.0 \%)$ \\
\cline { 2 - 3 } & Yes & $24(24.0 \%)$ \\
\hline \multirow{4}{*}{ Day } & Mean \pm SD & $2.13 \pm 0.99$ \\
\cline { 2 - 3 } & Day 1 & 6 \\
& Day 2 & 12 \\
& Day 3 & 4 \\
& Day 4 & 1 \\
Intervention & Day 5 & 1 \\
\cline { 2 - 3 } & Amiodarone & $19(79.2 \%)$ \\
\cline { 2 - 3 } & Direct current shock & $5(20.8 \%)$ \\
\hline
\end{tabular}

Age was proportionally related to development of POAF and the presence of hypertension was associated with development of POAF. Patients in POAF group were older than those who did not develop POAF. Patients with POAF has mean age of $(58.92 \pm 8.24)$ versus mean age of $(55.39 \pm 7.05)$ in patients without POAF with significant $(\mathrm{P}$ value $=0.043)$ : and the $P$. value was more significant in patients with history of hypertension ( $\mathrm{P}$ value $=0.0135)$ as there were 20 patients of total 24 patients (representing 83\%) who developed AF have history of hypertension versus 42 patients of total 76 patients (representing 55\%) who didn't develop AF have history of hypertension. There were no significant associations between gender, diabetes mellitus and history of smoking and occurrence of AF after $\mathrm{CABG}$ with $\mathrm{P}$ value: $0.793,0.058$ and 0.561 respectively (Table 3).

Table (3): Relationship between age, gender, DM, HTN \& smoking and the occurrence of POAF

\begin{tabular}{|c|c|c|c|c|}
\hline \multirow{2}{*}{\multicolumn{2}{|c|}{$\begin{array}{ll}\text { Parameter } & \mathrm{AF} \\
\end{array}$}} & No & Yes & \multirow{2}{*}{ P-value } \\
\hline & & No. $=76$ & No. $=24$ & \\
\hline \multirow{2}{*}{ Age } & Mean \pm SD & $55.39 \pm 7.05$ & $58.92 \pm 8.24$ & \multirow{2}{*}{0.043} \\
\hline & Range & $38-70$ & $40-77$ & \\
\hline \multirow{3}{*}{ Gender } & Females & $14(18.4 \%)$ & $5(20.8 \%)$ & \multirow{3}{*}{0.793} \\
\hline & Males & $62(81.6 \%)$ & $19(79.2 \%)$ & \\
\hline & Range & $1.6-2.3$ & $1.68-2.3$ & \\
\hline \multirow{2}{*}{$\mathrm{DM}$} & No & $39(51.3 \%)$ & $7(29.2 \%)$ & \multirow{2}{*}{0.058} \\
\hline & Yes & $37(48.7 \%)$ & $17(70.8 \%)$ & \\
\hline \multirow{2}{*}{ HTN } & No & $34(44.7 \%)$ & $4(16.7 \%)$ & \multirow{2}{*}{0.0135} \\
\hline & Yes & $42(55.3 \%)$ & $20(83.3 \%)$ & \\
\hline \multirow{2}{*}{ Smoking } & No & $36(47.4 \%)$ & $13(54.2 \%)$ & \multirow{2}{*}{0.561} \\
\hline & Yes & $40(52.6 \%)$ & $11(45.8 \%)$ & \\
\hline
\end{tabular}

Left ventricular Ejection fraction (EF) was inversely related to development of POAF. Patients with POAF has mean EF of $(43.42 \pm 7.03)$ vs mean EF of $(49.83 \pm$ 10.59) in patients without POAF with significant $(\mathrm{P}$ value $=0.007)$. Left ventricular internal dimension in diastole
(LVIDd): left ventricular internal dimension in systole (LVIDs): septal wall thickness, posterior wall thickness and left ventricular mass index (LVMI) were proportionally related to development of POAF where an increase in dimension, wall thickness or LV mass was associated 
with an increase in the incidence of $\mathrm{AF}$ with extremely significance $(\mathrm{P}$ value of $=$ $0.001)$ for the increased LVMI. There were no significant associations between increase in relative wall thickness (RWT) and occurrence of AF. Impaired right ventricular systolic function assessed by TAPSE increased the incidence of AF with significant $P$. value (0.011) (Table 4).

Table (4): Distribution of echocardiographic parameters in both AF and non-AF groups

\begin{tabular}{|c|c|c|c|c|}
\hline \multirow{2}{*}{\multicolumn{2}{|c|}{ Parameters $\quad$ AF }} & No & Yes & \multirow{2}{*}{ P-value } \\
\hline & & No. $=76$ & No. $=24$ & \\
\hline \multirow{2}{*}{$\mathrm{EF}$} & Mean \pm SD & $49.83 \pm 10.59$ & $43.42 \pm 7.03$ & \multirow{2}{*}{0.007} \\
\hline & Range & $24-78$ & $31-58$ & \\
\hline \multirow{2}{*}{ LVIDd } & Mean \pm SD & $5.05 \pm 0.54$ & $5.39 \pm 0.55$ & \multirow{2}{*}{0.008} \\
\hline & Range & $3.7-6$ & $4.5-6.9$ & \\
\hline \multirow{2}{*}{ LVIDs } & Mean \pm SD & $3.50 \pm 0.51$ & $3.96 \pm 0.70$ & \multirow{2}{*}{0.001} \\
\hline & Range & $2.2-4.6$ & $2.7-6$ & \\
\hline \multirow{2}{*}{ SWT } & Mean \pm SD & $10.50 \pm 1.63$ & $11.50 \pm 2.25$ & \multirow{2}{*}{0.019} \\
\hline & Range & $6-14$ & $6-16$ & \\
\hline \multirow{2}{*}{ PWT } & Mean \pm SD & $10.08 \pm 1.87$ & $11.29 \pm 1.81$ & \multirow{2}{*}{0.006} \\
\hline & Range & $6-16$ & $7-16$ & \\
\hline \multirow{2}{*}{ LVM } & Mean \pm SD & $193.67 \pm 42.08$ & $254.42 \pm 58.16$ & \multirow{2}{*}{0.000} \\
\hline & Range & $95-297$ & $118-373$ & \\
\hline \multirow{2}{*}{ LVMI } & Mean \pm SD & $96.79 \pm 20.61$ & $124.67 \pm 35.12$ & \multirow{2}{*}{0.000} \\
\hline & Range & $45-137$ & $55-212$ & \\
\hline \multirow{2}{*}{ RWT } & Mean \pm SD & $0.41 \pm 0.10$ & $0.42 \pm 0.07$ & \multirow{2}{*}{0.627} \\
\hline & Range & $0.23-0.86$ & $0.22-0.58$ & \\
\hline \multirow{3}{*}{ TAPSE } & Mean \pm SD & $21.70 \pm 4.12$ & $19.21 \pm 4.13$ & \multirow{3}{*}{0.011} \\
\hline & Range & $12-30$ & $12-27$ & \\
\hline & Range & $0.45-1.8$ & $0.64-1.9$ & \\
\hline
\end{tabular}

Left atrium diameter (LAD): left atrium volume index (LAVI): average E/e', septal E/e' and lateral E/e' were proportionally related to development of POAF. Patients with POAF have mean LAD and LAVI of $(4.00 \pm 0.37)$ and $(32.93 \pm 11.07)$ respectively versus mean LAD and LAVI of $(3.65 \pm 0.43)$ and $(25.65 \pm 6.70)$ respectively in patients without POAF with highly significant $\mathrm{P}$ value $=0.000)$. The mean average $\mathrm{E} / \mathrm{e}$ ' was $(8.73 \pm 2.31)$ in patients with POAF versus $(7.11 \pm 2.29)$ in patients without POAF with ( $\mathrm{P}$ value of 0.003$)$. Decrease of septal e' velocity was associated with increased incidence of POAF. On the other hand, there were no associations between decreases in lateral e' velocity or increase in TR velocity and development of POAF. Also, presence of mitral regurgitation didn't increase the occurrence of AF (Table 5). 
Table (5): Distribution of LAD, LAVI and diastolic dysfunction parameters in both AF and non-AF groups

\begin{tabular}{|c|c|c|c|c|}
\hline \multirow{2}{*}{\multicolumn{2}{|c|}{ Parameters $\quad$ AF }} & No & Yes & \multirow{2}{*}{ P-value } \\
\hline & & No. $=76$ & No. $=24$ & \\
\hline \multirow{2}{*}{ LAD } & Mean \pm SD & $3.65 \pm 0.43$ & $4.00 \pm 0.37$ & \multirow{2}{*}{0.000} \\
\hline & Range & $2.5-4.6$ & $3.3-4.7$ & \\
\hline \multirow{2}{*}{ LAVI } & Mean \pm SD & $25.65 \pm 6.70$ & $32.93 \pm 11.07$ & \multirow{2}{*}{0.000} \\
\hline & Range & $15-47$ & $18-57$ & \\
\hline \multirow{2}{*}{ Average E/e' } & Mean \pm SD & $7.11 \pm 2.29$ & $8.73 \pm 2.31$ & \multirow{2}{*}{0.003} \\
\hline & Range & $3.3-14$ & $4.6-12.9$ & \\
\hline \multirow{2}{*}{ Septal e' } & Mean \pm SD & $9.02 \pm 2.07$ & $7.79 \pm 1.85$ & \multirow{2}{*}{0.011} \\
\hline & Range & $5-14$ & $5-11.5$ & \\
\hline \multirow{2}{*}{ Lateral e' } & Mean \pm SD & $9.63 \pm 2.21$ & $9.39 \pm 2.52$ & \multirow{2}{*}{0.657} \\
\hline & Range & $5-17$ & $5.9-16$ & \\
\hline \multirow{2}{*}{ Septal E/e' } & Mean \pm SD & $7.38 \pm 2.37$ & $8.78 \pm 2.49$ & \multirow{2}{*}{0.015} \\
\hline & Range & $3.5-15$ & $5.2-14.5$ & \\
\hline \multirow{2}{*}{ Lateral E/e' } & Mean \pm SD & $6.65 \pm 2.17$ & $8.30 \pm 2.11$ & \multirow{2}{*}{0.001} \\
\hline & Range & $3-14$ & $5-12$ & \\
\hline \multirow{2}{*}{ TR velocity } & Mean \pm SD & $1.305 \pm 60.81$ & $1.367 \pm 55.36$ & \multirow{2}{*}{0.642} \\
\hline & Range & $0.35-2.85$ & $0.64-2.30$ & \\
\hline \multirow{4}{*}{ MR } & Non & $60(78.9 \%)$ & $13(54.2 \%)$ & \multirow{4}{*}{0.067} \\
\hline & Mild & $10(13.2 \%)$ & $6(25.0 \%)$ & \\
\hline & Moderate & $5(6.6 \%)$ & $5(20.8 \%)$ & \\
\hline & Severe & $1(1.3 \%)$ & $0(0.0 \%)$ & \\
\hline
\end{tabular}

A multivariate logistic regression analysis was performed to test the significance of the aforementioned risk factors and development of AF after CABG and demonstrated that age more than 60 years, hypertension, use of inotropes for more than 30 minutes, LVEF (<50\%): LVIDd (>53 mm): LVIDs (>40 mm): LVMI (> 117): TAPSE $(<18 \mathrm{~mm})$ : LAVI $(>33.5 \mathrm{ml} / \mathrm{m} 2)$ : average E/e' $(>7.4$ $\mathrm{ms})$ : septal e' $(<7.3 \mathrm{~ms})$ and all risk factors mentioned in table (8) except body surface area $(>1.97)$ were statistically significant and associated with development of AF after CABG (Table 6). 
PREDICTORS OF ATRIAL FIBRILLATION AFTER CABG ASSESSED...

Table (6): Univariate logistic regression analysis for factors associated with $\mathrm{AF}$

\begin{tabular}{|c|c|c|c|c|c|c|c|}
\hline \multirow{2}{*}{$\begin{array}{l}\text { Analysis } \\
\text { Parameters }\end{array}$} & \multirow{2}{*}{ B } & \multirow{2}{*}{ S.E. } & \multirow{2}{*}{ Wald } & \multirow{2}{*}{ P-value } & \multirow{2}{*}{$\begin{array}{c}\text { Odds } \\
\text { ratio }(\mathrm{OR})\end{array}$} & \multicolumn{2}{|c|}{ 95\% C.I. for OR } \\
\hline & & & & & & Lower & Upper \\
\hline Age $>60$ & 1.099 & 0.487 & 5.096 & 0.024 & 3.000 & 1.156 & 7.787 \\
\hline BSA > 1.97 & 0.904 & 0.491 & 3.398 & 0.065 & 2.471 & 0.944 & 6.463 \\
\hline HTN & 1.398 & 0.594 & 5.534 & & 4.048 & 1.263 & 12.974 \\
\hline Inotrope & 1.237 & 0.595 & 4.315 & 0.038 & 3.444 & 1.072 & 11.064 \\
\hline $\mathrm{EF}<=50$ & 1.662 & 0.594 & 7.833 & 0.005 & 5.270 & 1.646 & 16.878 \\
\hline LVIDd $>5.3$ & 1.110 & 0.482 & 5.300 & 0.021 & 3.033 & 1.179 & 7.802 \\
\hline LVIDs $>4$ & 2.121 & 0.570 & 13.836 & 0.000 & 8.341 & 2.728 & 25.503 \\
\hline SWT >11 & 1.284 & 0.489 & 6.908 & & 3.611 & 1.386 & 9.408 \\
\hline PWT $>10$ & 1.600 & 0.511 & 9.801 & & 4.954 & 1.819 & 13.492 \\
\hline LVM $>233$ & 2.561 & 0.548 & 21.821 & & 12.952 & 4.422 & 37.937 \\
\hline LVMI >117 & 2.089 & 0.520 & 16.129 & 0.000 & 8.077 & 2.914 & 22.388 \\
\hline TAPSE $\leq 18$ & 1.236 & 0.501 & 6.087 & 0.01 & 3.441 & 1.289 & 9.184 \\
\hline $\mathrm{LAD}>3.7$ & 1.546 & 0.553 & 7.818 & 0.005 & 4.694 & 1.588 & 13.877 \\
\hline LAVI $>33.5$ & 2.120 & 0.594 & 12.758 & 0.000 & 8.333 & 2.603 & 26.675 \\
\hline Average E/e' > 7.4 & 1.933 & 0.533 & 13.136 & 0.000 & 6.913 & 2.430 & 19.667 \\
\hline Septal e' $<=7.3$ & 1.914 & 0.511 & 14.040 & 0.000 & 6.778 & 2.491 & 18.442 \\
\hline Septal E/e' >7.6 & 1.483 & 0.509 & 8.491 & 0.004 & 4.407 & 1.625 & 11.953 \\
\hline Lateral E/e' > 7.6 & 1.833 & 0.507 & 13.070 & 0.000 & 6.250 & 2.314 & 16.879 \\
\hline
\end{tabular}

A multivariate logistic regression analysis was performed to determine the most important risk factors that were associated with occurrence of postoperative $\mathrm{AF}$ and demonstrated that dilated LA (OR: 7.8; 95\% CI 0.96-64): septal e' velocity (OR: 6.48; 95\% CI 0.946): septal wall thickness (OR: 6; 95\% CI
0.59-61): lateral E/e' velocity (OR: 4.59; 95\% CI.149-141): LAVI (OR: 4.4; 95\% CI 0.59-32): hypertension (OR: $5.3 ; 95 \%$ CI.49-57): LVM (OR: 5.5; 95\% CI 0.148205):) and impaired LV function (OR: 3; 95\% CI 0.37-25) were the most important independent risk factors for development of AF after CABG (Table 7). 
Table (7): Multi-variate logistic regression analysis for factors associated with AF

\begin{tabular}{|c|c|c|c|c|c|c|c|}
\hline \multirow{2}{*}{$\begin{array}{l}\text { Analysis } \\
\text { Parameters }\end{array}$} & \multirow{2}{*}{ B } & \multirow{2}{*}{ S.E. } & \multirow{2}{*}{ Wald } & \multirow{2}{*}{ P-value } & \multirow{2}{*}{$\begin{array}{c}\text { Odds } \\
\text { ratio }(\mathrm{OR})\end{array}$} & \multicolumn{2}{|c|}{ 95\% C.I. for OR } \\
\hline & & & & & & Lower & Upper \\
\hline Age $>60$ & 0.413 & 0.873 & 0.224 & 0.636 & 1.512 & 0.273 & 8.363 \\
\hline HTN & 1.677 & 1.213 & 1.910 & 0.167 & 5.348 & 0.496 & 57.677 \\
\hline Inotrope & 0.145 & 1.177 & 0.015 & 0.902 & 1.156 & 0.115 & 11.613 \\
\hline $\mathrm{EF}<=50$ & 1.130 & 1.074 & 1.108 & 0.292 & 3.097 & 0.378 & 25.405 \\
\hline LVIDd $>5.3$ & 0.205 & 1.230 & 0.028 & 0.868 & 1.227 & 0.110 & 13.663 \\
\hline LVIDs $>4$ & 0.786 & 1.529 & 0.264 & 0.607 & 2.194 & 0.110 & 43.927 \\
\hline SWT > 11 & 1.798 & 1.181 & 2.317 & 0.128 & 6.037 & 0.596 & 61.123 \\
\hline PWT $>10$ & 0.284 & 1.251 & 0.051 & 0.821 & 1.328 & 0.114 & 15.426 \\
\hline LVM $>233$ & 1.706 & 1.846 & 0.854 & 0.356 & 5.505 & 0.148 & 205.201 \\
\hline LVMI >117 & 0.027 & 1.366 & 0.000 & 0.984 & 1.027 & 0.071 & 14.952 \\
\hline TAPSE $\leq 18$ & 0.142 & 1.019 & 0.020 & 0.889 & 1.153 & 0.156 & 8.498 \\
\hline $\mathrm{LAD}>3.7$ & 2.062 & 1.073 & 3.693 & 0.055 & 7.863 & 0.960 & 64.407 \\
\hline LAVI >33.5 & 1.482 & 1.022 & 2.105 & 0.147 & 4.404 & 0.594 & 32.626 \\
\hline Average E/e' >7.4 & 0.424 & 2.147 & 0.039 & 0.843 & 1.529 & 0.023 & 102.776 \\
\hline Septal $\mathrm{e}^{\prime}<=7.3$ & 1.870 & 1.006 & 3.455 & 0.063 & 6.487 & 0.903 & 46.577 \\
\hline Septal E/e' > 7.6 & 1.021 & 1.524 & 0.449 & 0.503 & 2.776 & 0.140 & 55.008 \\
\hline Lateral E/e' >7.6 & 1.524 & 1.749 & 0.759 & 0.384 & 4.591 & 0.149 & 141.484 \\
\hline
\end{tabular}

\section{DISCUSSION}

Our study was conducted on 100 patients who had underwent CABG with the incidence of POAF was about $24 \%$ with the peak incidence of POAF was in the second day, similar results were reported by Dave et al. (2018). It has been consistently reported that the incidence of POAF range between $10 \%$ and $65 \%$ (Alqahtani, 2010).

The present study found that older people have higher risk of POAF but no significant difference between male and female gender. Advanced age is the most consistently reported and widely accepted risk factor for POAF (January et al., 2014). The aging process leads to a loss of myocardial fibers, increased fibrosis and collagen deposition in the atria, particularly near the sinoatrial node, which alters atrial electrical properties. Age-related physiological changes are a 'setup' for POAF, with acute surgical trauma and inflammation likely providing the inciting factors that induce POAF (Philip et al., 2014). However, a study by Aranki et al. (2010) reported that male gender is an independent predictor for the development of postoperative AF.

In our study, history of hypertension was strongly associated with development of POAF although diabetes was not. These results were consistent with Dave et al. (2018) where they found no association between DM and POAF, however other studies found significant association between them (Alqahtani, 2010). Hypertension is considered one of the most important risk factors of $\mathrm{AF}$ in general population (Hindricks et al., 2020) and also after CABG (Burrage et al., 2019). Hypertension-related structural changes may have a significant role in the genesis of associated arrhythmias. A number of changes in the hypertrophied heart, such as fibrosis, may act as a substrate for reentry arrhythmias (Aranki et al., 2010). 
Multiple studies demonstrated the effect of prolonged bypass time (CPB) on cardiopulmonary machine and prolonged aortic cross- clamp time on development of POAF (Dave et al., 2018 and Gudbjartsson et al., 2020). However, in our study there were no significant differences in both $\mathrm{AF}$ and non-AF groups with more prolonged bypass time or aortic cross-clamp time. But of note, we excluded patients with history of prolonged bypass time and cross clamp time as it is defined as a risk factor for development of POAF. CPB is associated with an ischemia-reperfusion injury inducing a complex inflammatory response, the analogous of which have been reported in patients with AF. These ranged from the presence of inflammatory infiltrates in atrial biopsies to increased concentrations of C-reactive protein which form the substrate for generation of ectopic activity (Helgadottir et al., 2012). Also, there was no difference in patients with history of complete revascularization and incomplete revascularization in occurrence of AF.

In our study, use of adrenaline was associated with higher incidence of POAF. Hashemzadeh et al. (2013) reported similar findings. Several studies have suggested that use of inotropes increase the sympathetic activity and this heightened sympathetic response predisposes a patient to developing POAF (Workman, 2010 and Hashemzadeh et al., 2013).

In the present study, impaired LV systolic function (ejection fraction) and impaired RV systolic function (TAPSE) increased the occurrence of $\mathrm{AF}$ and that was consistent with results reported by
Dave et al. (2018) when they demonstrated that reduced ejection fraction was strongly associated with development of POAF after CABG surgery and also it is reported that heart failure is an independent risk factor (Banach et al., 2010). A study conducted by Ting et al. (2017) showed that RV dysfunction is associated significantly with the occurrence of POAF in the context of cardiac surgery.

Increased left ventricular internal dimensions (systolic and diastolic): increased septal wall thickness, increased posterior wall thickness and LV mass index were significantly associated with development of POAF in this study. In agreement with the present work, other studies revealed a significant association between increased LV dimensions and LV hypertrophy and development of POAF (Burrage et al., 2019 and Gudbjartsson et al., 2020). In patients with LV hypertrophy, diastolic dysfunction, advanced age, myocardial ischemia, and myocardial fibrosis in addition to structural abnormalities with hypertrophy that include myocardial cell disarray, coronary microvasculature dysfunction and remodeling changes may predispose to AF (Tian et al., 2018). In patients with dilated dimensions diffuse fibrosis or alterations in the structure or LV function may provide a substrate for AF (Zecchin et al., 2019).

The present study showed that increased left atrial diameter and indexed volume increased the incidence of POAF significantly. It is well documented in multiple studies that increased LA volume or diameter is an important independent predictor of POAF which support our 
results, patients who developed POAF after CABG had more fibrosis and increased LAVI (Ozben et al., 2016 and Gudbjartsson et al., 2020). Larger postoperative LAVI was an independent predictor for the occurrence of AF (Kang et al., 2018). Larger atria may alter atrial electrophysiological properties and increase susceptibility to POAF (Greenberg et al., 2017).

There was association between increased septal E/e', lateral E/e' and average $\mathrm{E} / \mathrm{e}^{\prime}$ and decreased lateral $\mathrm{e}^{\prime}$ and occurrence of POAF but that didn't happen with decreased septal e'. Despite the hypothesis that increased E/e' associated with impaired relaxation and diastolic dysfunction and increased LVEDP which predispose to POAF, Rader et al. (2012) did not find significant association between E/e' and postoperative $\mathrm{AF}$ after cardiac surgery. However, E/e', an established surrogate of LVEDP, has been shown to be predictive for AF after lung transplant (Nojiri et al., 2010).

In our study there was no significant association between occurrence of AF and increased tricuspid regurgitation velocity (TR velocity) or presence of mitral regurgitation. However, Ronsoni et al. (2020) stated that the presence of mitral valve disease was a predictor of POAF and increases the risk by 2.3 -fold.

In the present work, a multivariate logistic regression analysis was performed to determine the most important risk factors that were associated with occurrence of postoperative $\mathrm{AF}$ and demonstrated that dilated LA, septal e' velocity, septal wall thickness, lateral E/e' velocity, LAVI, hypertension, LVM and impaired LV function were the most important independent risk factors for development of AF after CABG.

\section{CONCLUSION}

The incidence of POAF was $24 \%$ with peak incidence in the second postoperative day. Echocardiography was an essential tool for detection of other predictors where low ejection fraction, impaired RV systolic function (reduced TPASE): increased LV internal dimensions and increased LV walls thickness were important predictors for occurrence of POAF.

Dilated left atrium and increased left atrium volume index were significant predictors of atrial fibrillation after CABG. Tissue Doppler-derived measurements may serve as a tool for determination of POAF predictors and patients with high risk as increased average $\mathrm{E} / \mathrm{e}^{\prime}$, septal $\mathrm{E} / \mathrm{e}$ ', lateral $\mathrm{E} / \mathrm{e}$ ' velocities and decreased lateral e' velocity but not septal e' velocity were associated with higher incidence of POAF.

\section{REFERENCES}

1. Alqahtani AAR (2010): Atrial fibrillation post cardiac surgery trends toward management. The Official Journal of the Gulf Heart Association, 11(2): 57-63.

2. Aranki SF, Shaw DP, Adams DH, Rizzo RJ, Couper GS, VanderVliet M, Collins JJ, Cohn LH, Burstin HR (2010): Predictors of atrial fibrillation after coronary artery surgery: current trends and impact on hospital resources. Circulation, 94(3):390397.

3. Banach M, Rysz J, Drozdz J, Okonski P, Misztal M, Barylski M, Irzmanski $R$ and Zaslonka J (2010): Risk Factors of Atrial Fibrillation Following Coronary Artery Bypass Grafting. Circulation Journal, 70(4): 438-441. 
4. Bidar E, Bramer S, Maesen B, Maessen J and Schotten U. (2013): Post-operative atrial fibrillation-pathophysiology, treatment and prevention. Journal of Atrial Fibrillation, 5(6): 781-788.

5. Burrage PS, Low YH, Campbell NG and O'Brien B (2019): New-Onset Atrial Fibrillation in Adult Patients After Cardiac Surgery. Current Anesthesiology Reports, 9(2): 174-193.

6. Dave S, Nirgude A, Gujjar P and Sharma $R$ (2018): Incidence and risk factors for development of atrial fibrillation after cardiac surgery under cardiopulmonary bypass. Indian Journal of Anaesthesia, 62(11): 887891.

7. Greenberg JW, Lancaster TS, Schuessler RB and Melby SJ (2017): Postoperative atrial fibrillation following cardiac surgery: a persistent complication. European Journal of Cardio-Thoracic Surgery, 52(4): 665-672.

8. Gudbjartsson T, Helgadottir S, Sigurdsson MI, Taha A, Jeppsson A, Christensen TD and Riber LPS (2020): New-onset postoperative atrial fibrillation after heart surgery. Acta Anaesthesiologica Scandinavica, 64(2): 145-155.

9. Hashemzadeh $K$, Dehdilani $M$ and Dehdilani M. (2013): Postoperative Atrial Fibrillation following Open Cardiac Surgery: Predisposing Factors and Complications. J Cardiovasc Thorac Res., 5(3):101-7.

10. Helgadottir S, Sigurdsson MI, Ingvarsdottir IL, Arnar DO and Gudbjartsson T (2012): Atrial fibrillation following cardiac surgery: risk analysis and long-term survival. Journal of Cardiothoracic Surgery, 7: 87-95.

11. Hindricks G, Potpara T, Dagres N, Arbelo E, Bax JJ, Blomstro C, Boriani G, Castella M, Dan GA, Dilaveris PE and Fauchier $\mathbf{L}$. (2020): ESC Guidelines for the diagnosis and management of atrial fibrillation developed in collaboration with the European Association of Cardio-Thoracic Surgery (EACTS). European Heart Journal, 20: 363-268.

12. January CT, Wann LS, Alpert JS, Calkins H, Cigarroa JE, Cleveland JC, Conti JB,
Ellinor PT, Ezekowitz MD and Field ME. (2014): 2014 AHA/ACC/HRS guideline for the management of patients with atrial fibrillation: a report of the American College of Cardiology/American Heart Association Task Force on Practice Guidelines and the Heart Rhythm Society. Journal of the American College of Cardiology, 64(21): 176.

13. Kang MK, Joung B, Shim CY, Cho IJ, Yang WI, Moon J, Jang Y, Chung N, Chang BC and Ha JW (2018): Postoperative left atrial volume index is a predictor of the occurrence of permanent atrial fibrillation after mitral valve surgery in patients who undergo mitral valve surgery. Cardiovascular Ultrasound, 16(1): 5-9.

14. Magne J, Salerno B, Mohty D, Serena C, Rolle F, Piccardo A and Aboyans V. (2019): Echocardiography is useful to predict postoperative atrial fibrillation in patients undergoing isolated coronary bypass surgery: A prospective study. Acute Cardiovascular Care, 8(2): 104-113.

15. Members ATF, Camm AJ, Lip GY, De Caterina R, Savelieva I, Atar D, Guidelines EC. (2012): 2012 focused update of the ESC guidelines for the management of atrial fibrillation: an update of the 2010 ESC guidelines for the management of atrial fibrillation developed with the special contribution of the European Heart Rhythm Association. European Heart Journal, 33(21): 2719-2747.

16. Nojiri T, Maeda H, Takeuchi Y, Funakoshi $\mathbf{Y}$, Maekura $\mathbf{R}$, Yamamoto $\mathrm{K}$ and Okumura M (2010): Predictive value of preoperative tissue Doppler echocardiographic analysis for postoperative atrial fibrillation after pulmonary resection for lung cancer. The Journal of Thoracic and Cardiovascular Surgery, 140(4): 764-768.

17. Ozben B, Akaslan D, Sunbul M, Filinte D, Ak K, Sari I, Tigen $K$ and Basaran $Y$ (2016): Postoperative Atrial Fibrillation after Coronary Artery Bypass Grafting Surgery: A Two-dimensional Speckle Tracking Echocardiography Study. Heart, Lung \& Circulation, 25(10): 993-999. 


\section{AHMED A. RYAD et al.,}

18. Philip I, Berroëta C and Leblanc I (2014): Perioperative challenges of atrial fibrillation. Current Opinion in Anesthesiology, 27(3): 344-352.

19. Rader F, Gajulapalli RD, Pasala $T$ and Einstadter D. (2012): Abnormal Left Ventricular Filling and Postoperative Atrial Fibrillation After Cardiac Surgery. Journal of Atrial Fibrillation, 5(3): 634-8.

20. Ronsoni R, Leiria TL, Pires LM, Kruse ML, Pereira E, Silva RG and Lima GG (2020): Internal Validation of a Risk Score for Prediction of Postoperative Atrial Fibrillation after Cardiac Surgery. International Journal of Cardiovascular Sciences, 33(2): 158-166.

21. Tian H, Cui J, Yang C, Hu F, Yuan J, Liu S, Yang W, Jiang $X$ and Qiao $S$ (2018): Left ventricular remodeling in hypertrophic cardiomyopathy patients with atrial fibrillation. BMC Cardiovascular Disorders, 18(1): 207-212.
22. Ting PC, Chou AH, Chien-Chia Wu V, Tsai FC, Chu JJ, Chen CY, Lan TY and Chen SW (2017): Relationship Between Right Ventricular Function and Atrial Fibrillation After Cardiac Surgery. Journal of Cardiothoracic and Vascular Anesthesia, 31(5): 1663-1671.

23. Workman AJ (2010): Mechanisms of postcardiac surgery atrial fibrillation: more pieces in a difficult puzzle. Heart Rhythm, 6(10): 1423-1424.

24. Zecchin M, Muser D, Vitali-Serdoz L, Buiatti $A$ and Morgera $T$ (2019): Arrhythmias in Dilated Cardiomyopathy: Diagnosis and Treatment BT - Dilated Cardiomyopathy. Plb. Springer International Publishing, Pp. 149-171. 
تتبؤات حدوث الرجفة الأذينية بعد عمليات توصيل الثر ايين

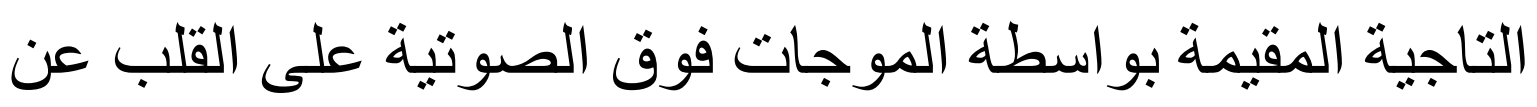
طريق الصدر

أحمد عبد المجيد رياض فرج, ياسر رضوان محمد رضوان, أحمد محمد صلاح الدين أحمد

قسم أمراض القلب, كلية الطب، جامعة الازهر

E-mail: ryadelfarra@gmail.com

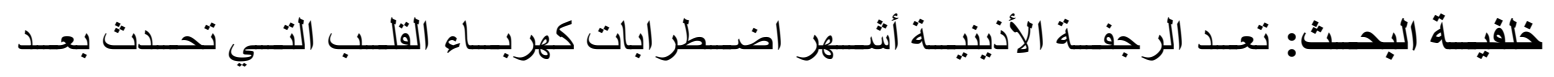

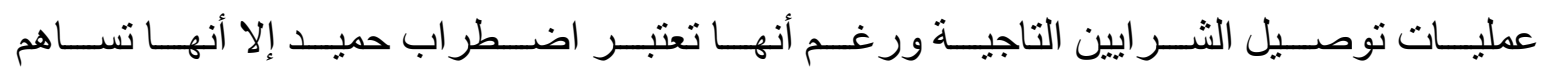

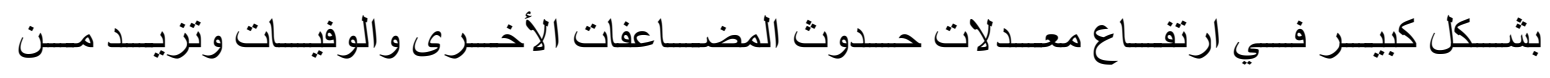
مدة بقاء المريض بالمستشفى بعد إجر اء الجر احة.

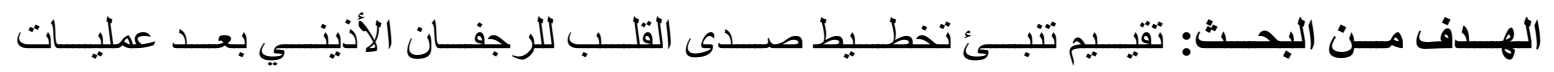
توصيل الثر ايين التاجية.

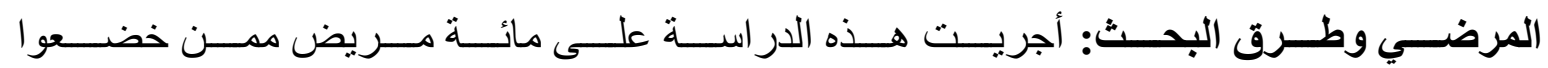

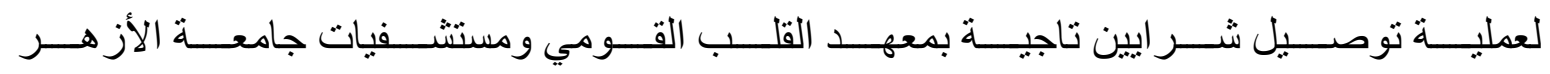

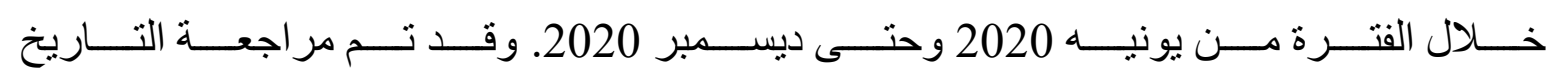

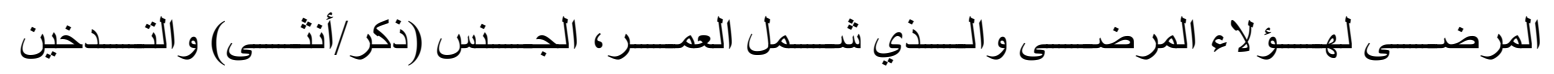

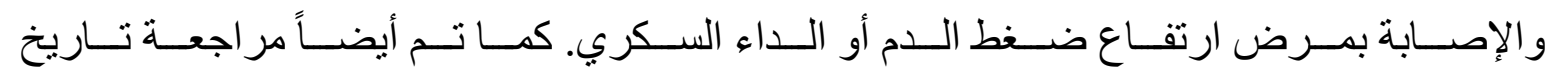

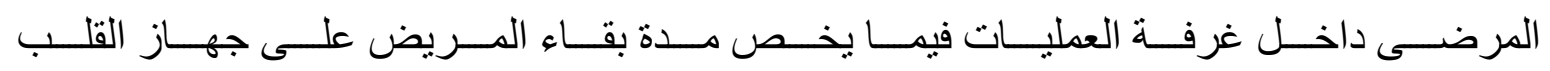
و الرئة الصناعي و عدد الطعوم التي تم ذر اعتها على الثر ايين التاجية.

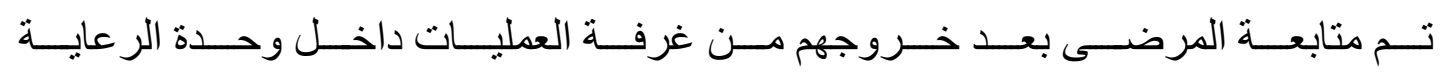

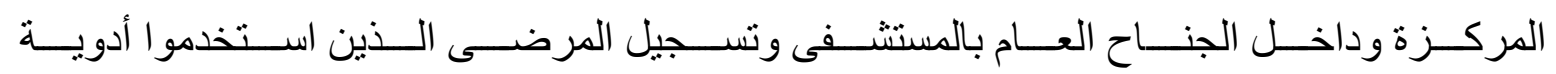

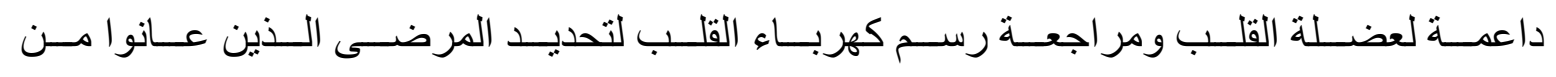
حدوث رجفان أذينية والوسيلة المستخدمة لعلاج هذا الاضطر ابعة 


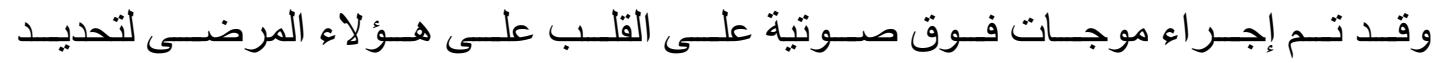

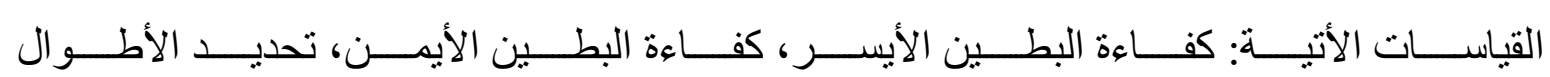

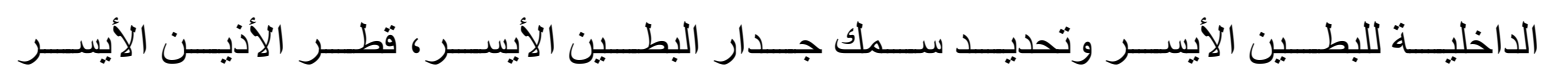

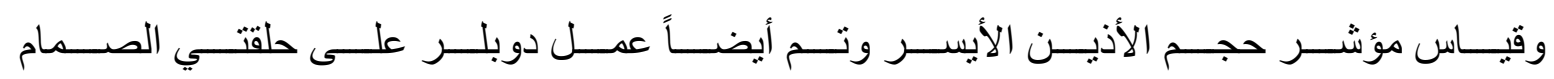

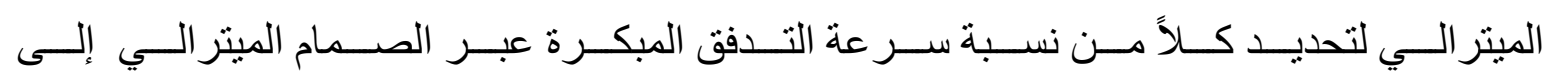

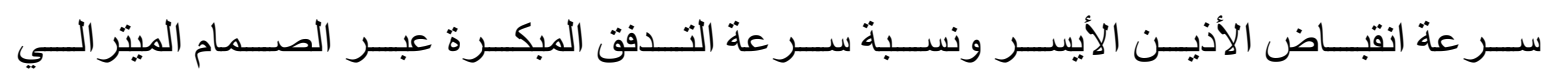

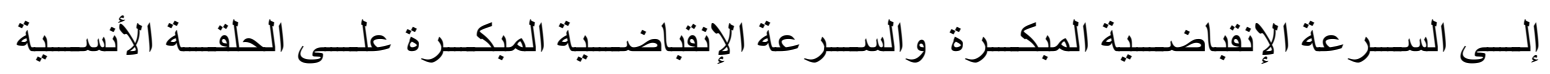
و السر عة الإنقباضية المبكرة على الحلقة الجانبية للصمام الميتر الي.

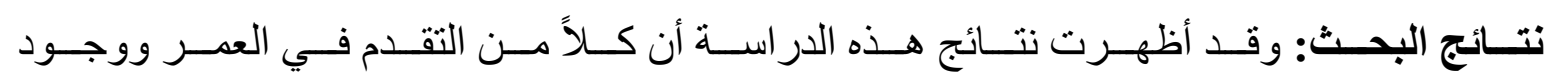

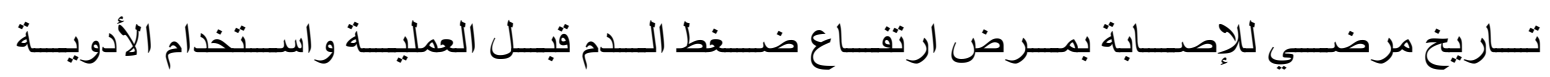

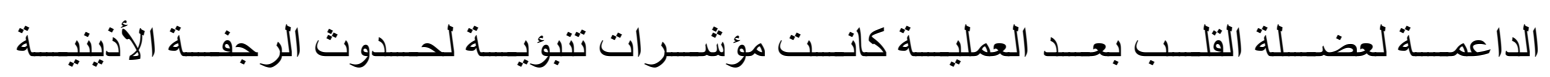

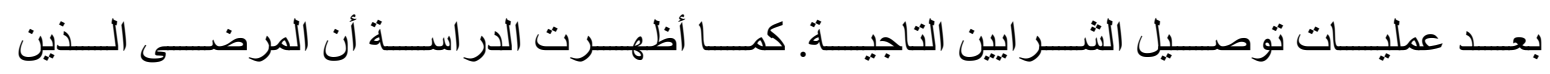

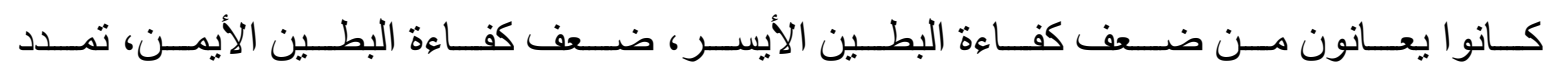

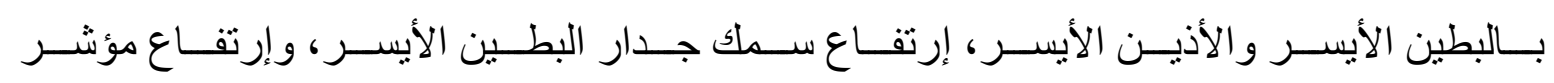

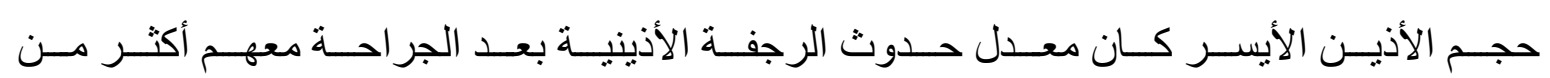
غير هم من المرضى.

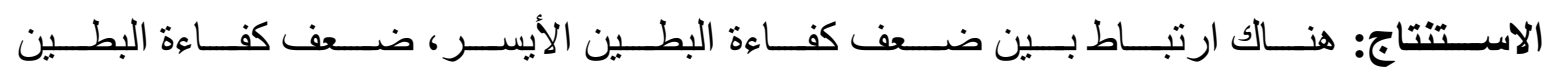

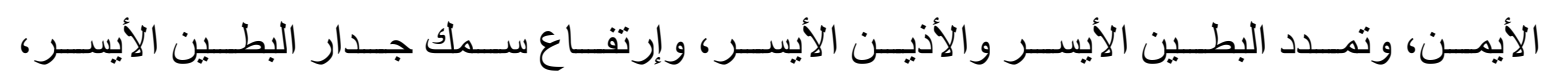

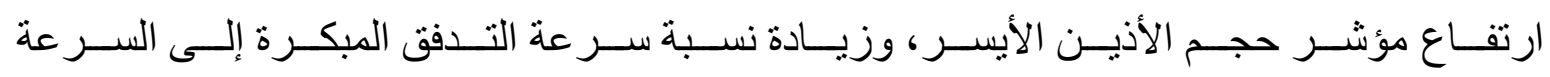

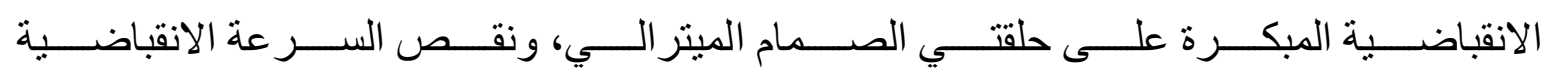

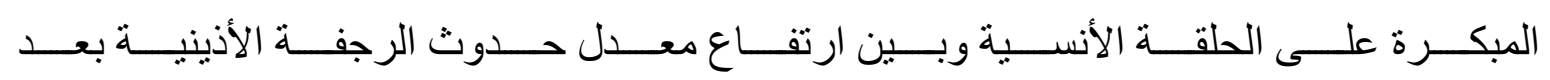

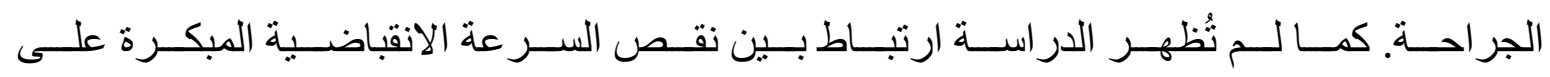
الحلقة الجانبية للصمام الميتر الي وحدوث الرجفة الأذينية.

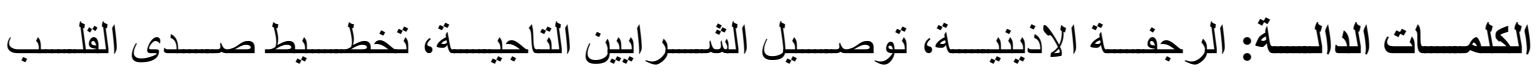

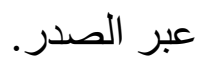

